В. ВОЛКОВ, С. ВЯЗБМЕНСКИИ, Л. МАЛЫШЕВ, О. МАМАЕВА, В. ПАВИЛАЙНЕН, Ю. САУЛГОЗИС

\title{
ИССЛЕДОВАНИЯ НАПРЯЖЕННОГО СОСТОНИЯ РОГОВИЦЫ ЖИВОГО ГЛАЗА ЧЕЛОВЕКА МЕТОДОМ ФОТОУПРУГОСТИ
}

\author{
(Представил Х. Абен)
}

\section{1. Введение}

Сравнительно новой и недостаточно изученной областью является использование метода фотоупругости для изучения напряженно-деформированного состояния роговой оболочки живого глаза человека с целью диагностики офтальмологических заболеваний. В последние годы в отечественной и зарубежной литературе опубликованы сообщения о применении метода фотоупругости для исследования двулучепреломляющих характеристик роговицы живого глаза, содержащие ряд существенных для рассматриваемой проблемы результатов $\left[{ }^{1-5}\right]$.

Вместе с тем в имеющейся литературе можно отметить недостаточное внимание к изучению фундаментальных вопросов явления двулучепреломления роговицы глаза in vivo, в частности, вопросов определения физико-механических и оптических свойств биоткани роговой оболочки, а также методики расшифровки получаемой картины полос изохром и изоклин. Вследствие этого допускаются неточности, а иногда и ошибочные интерпретации картины полос роговицы живого глаза при офтальмологических заболеваниях.

Авторами этой работы проведены исследования для обоснования и совершенствования метода фотоупругости как средства диагностики глазных заболеваний в состоянии in vivo. Несомненным достоинством метода фотоупругости при решении данной проблемы является возможность анализа натяжений биоткани роговицы и осуществления их бесконтактных измерений, диагносцирования нарушений нормального функционирования роговицы по изменениям ее картины фотоупругих полос относительно «нормы».

\section{2. Постановка задачи исследований}

Роговица является участком наружной (фиброзной) оболочки глазного яблока, составляющим по площади примерно $1 / 6$ ее часть. Она прозрачна, отличается оптической гомогенностью, хотя состоит из многих слоев. Поверхность роговой оболочки гладкая, зеркально блестящая. Горизонтальный и вертикальный диаметры роговицы составляют соответственно 11 и 10 мм, толщина оболочки в центральной части $0,4-0,6$ мм и на периферии $0,8-1,0$ мм, радиус роговицы составляет $7,8 \mathrm{~m}$, 


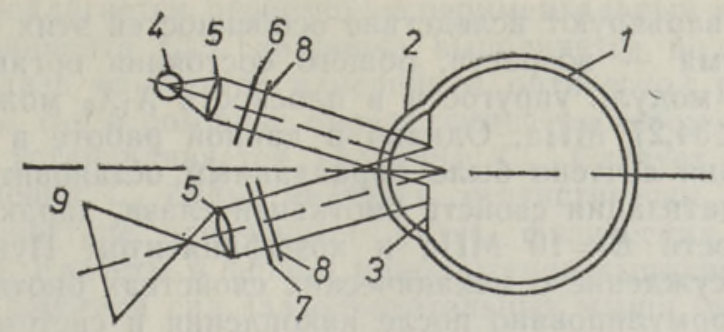

Рис. 1. Схема экспериментальной установки: 1 - глазное яблоко, 2 - роговица, 3 - радужная оболочка, 4 - источник света, 5 - объектив, 6 - поляризатор, 7 - анализатор, 8 - фнльтры круговой поляризации света, 9 - плоскость изображения.

Визуализация вынужденного двулучепреломления роговицы живого глаза осуществляется с помощью полярископа отражательного типа (рис. 1). Оптически чувствительной средой является биоткань роговицы, роль отражающей поверхности выполняет радужная оболочка глаза. Фотографическая фиксация картины полос изохром и изоклин осуществляется в монохроматическом или белом свете. В последнем случае получаются цветные диапозитивы. В качестве примера на рис. 2 представлена фотография поля изохром в монохроматическом освещении роговицы. Картина изохроматического поля характеризуется двумя порядками полос зеленого цвета (соответственно 1-й и 2-й зеленый), образующих ромбовидную фигуру. Распределение изохром по полю роговицы здорового глаза достаточно симметрично относительно зрачка. Расстояние между изохромами и их ширина позволяют судить о градиенте натяжений в роговице. Картина полос свидетельствует о небольших натяжениях роговицы вблизи зрачка и их возрастании в направлении к лимбу. На рис. 2 видна также изоклина параметра примерно $0^{\circ}-2^{\circ}$, образующая крестообразную фигуру.

Основными нагрузками на роговицу могут быть названы внутриглазное давление (ВГД), а также воздействия прямых вертикальных и горизонтальных глазодвигательных мышц. Для выявления физических предпосылок вынужденного двулучепреломления в роговице живого глаза проведены опыты на глазном яблоке человека тотчас после энуклеации глаза. В энуклеированном глазу воздействия глазодвигательных мышц отсутствуют и роговица оказывается нагруженной только ВГД. В этом случае наблюдавшиеся в роговице полосы изохром приобретают форму концентрических окружностей. Таким образом, переход от кругового очертания изохром к ромбовидному представляется обусловленным воздействием прямых глазодвигательных мышц, сообщающих роговице дополнительные, симметрично приложенные, натяжения по вертикальному и горизонтальному направлениям глазного яблока. На основании выполненных экспериментов, а также данных $\left[{ }^{2,6}\right]$ эффект двулучепреломления роговицы является суммарным и может быть объяснен воздействиями нагрузок ВГД и глазодвигательных мышц, а также свойствами молекулярно-клеточного строения ее биоткани $\left[{ }^{1}\right]$. Поспедний вид двулучепреломления роговой оболочки в рамках данной работы не изучался, однако, согласно $\left[{ }^{1}\right]$, его величина может составлять примерно $1 / 3-1 / 10$ полосы первого зеленого цвета. Механические исследования на растяжение образцов биоткани энуклеированных глаз человека показали следующее. Биоткани роговицы и склеры представляют собой монотропную среду с изотропией в плоскости $X_{1}$ и $X_{2}$. Индексы 1 и 2 соответствуют вертикальному и горизонтальному направлениям относительно глазного яблока; начало осей совмещено с центром зрачка. Механические свойства биотканей рого- 
вицы и склеры варьируют вследствие особенностей этих тканей у каждого индивидуума - возраста, общего состояния организма и т. д.. Так, например, модуль упругости в плоскости $X_{1} X_{2}$ может составлять 2,95 МПа $<E<34,27$ МПа. Однако в данной работе в качестве первого приближения сочтено было оправданным остановиться на линейно-упругой схематизации свойств биотканей глаза, характеризующихся модулем упругости $E=10$ МПа и коэффициентом Пуассона $v=0,4$. Окончательное суждение о механических свойствах биоткани роговицы может быть сформулировано после накопления и систематизации экспериментальных данных.

\section{3. Расчетно-эксперименальный метод определения коэффициента оптической чувствительности биоткани роговицы}

Для количественной расшифровки картины полос изохром, определяющей напряженно-деформированное состояние роговицы живого глаза при воздействиях ВГД и сил глазодвигательного аппарата, необходимо располагать значениями коэффициента оптической чувствительности $C_{\sigma}$. Этот коэффициент связывает напряжения (натяжения) в роговице с оптической разностью хода известной формулой [ $\left.{ }^{7}\right]$

$$
\sigma_{1 T}-\sigma_{2 T}=\frac{\delta}{C_{\sigma} h}
$$

где $\delta$ - оптическая разность хода, $\sigma_{1 T}, \sigma_{2 T}$ - равномерно распределенные по толщине натяжения роговицы, $h$ - толщина роговицы.

Обычный метод определения $C_{\sigma}$ тарировочными испытаниями в данном случае сопряжен с практически непреодолимыми трудностями прямых измерений натяжений тарируемой роговицы in vivo для вычисления $C_{\sigma}$.

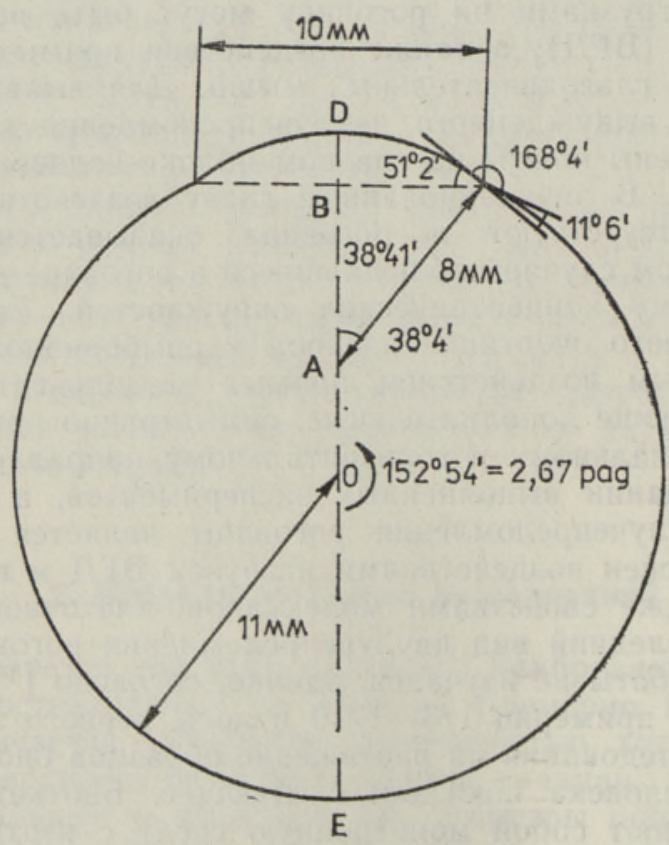

Рис. 3. Расчетная схема сферической оболочки глазного яблока и роговицы при действии внутриглазного давления. 
Авторами предла̄гается расчетно-экспериментальный подход к определению коэффициента $C_{\sigma}$. Тарировка выполняется по изохроматической картине глаза «в норме» измерением оптической разности хода. Напряжения $\sigma_{1 T}, \sigma_{2 T}$ в роговице определяются расчетом, после чего по формуле (3.1) устанавливается величина $C_{\sigma}$. Следует отметить, что найденные значения $C_{\sigma}$ будут являться статистически осредненными величинами вследствие отмеченных ранее физических особенностей биотканей глаза. Расчеты в первом приближении выполнялись для случая отсутствия действия сил глазодвигательных мышц, так как из экспериментальных результатов видно их значение в формировании контура изохроматического узора и малосущественное влияние на величину оптической разности хода. Глаз схематизировался системой двух сочлененных незамкнутых сферических оболочек постоянной толщины - роговицы (оболочка I) и склеральный оболочки (оболочка II). Нагрузкой оболочек являлось ВГД, составлявшее 19 мм рт. ст. (0,0025 МПа) (рис. 3).

Расчеты системы двух сопряженных тонких сферических оболочек I и II выполнялись по теории тонких изотропных оболочек. В случае осесимметричной деформации система разрешающих уравнений оболочки I, согласно $\left[{ }^{8}\right]$, имеет вид:

$$
\begin{gathered}
\Delta U+2 U=\frac{R^{2}\left(1-v^{2}\right)}{E h}\left[q_{n}-\left(\frac{d q_{\tau}}{d \theta}+q_{\tau} \operatorname{ctg} \theta\right)\right], \\
\Delta \Delta w+2 \Delta w+4 b^{4} w+\frac{4 b^{4}}{1-v} U= \\
=\frac{R^{2}\left(1-v^{2}\right)}{E h}\left[q_{n} \frac{12 R^{2}}{h}-\left(\frac{d q_{\tau}}{d \theta}+q_{\tau} \operatorname{ctg} \theta\right)\right]
\end{gathered}
$$

где $\Delta$ - дифференциальный оператор второго порядка, $q_{n}$ и $q_{\tau}-$ coответственно нормальная и касательная компоненты поверхностной симметричной нагрузки, $U-$ вспомогательная функция В. В. Новожилова, связанная с перемещениями в направлениях касательной к меридиану $(u)$ и нормали к поверхности (w) соотношением

$$
U=\frac{d U}{d \theta}+u \operatorname{ctg} \theta+(1+v) w .
$$

В рассматриваемой задаче компонента $q_{\tau}$ отсутствует, а компонента $q_{n}$ представляет собой интенсивность ВГД, т. е. $q_{n}=q_{0}$. При этих условиях частное решение системы (3.2) определяется как

$$
w^{*}=\frac{1-v}{2} \frac{q_{0} R^{2}}{E h}, \quad U^{*}=\frac{1-v^{2}}{2} \frac{q_{0} R^{2}}{E h}=(1+v) w^{*} .
$$

Из (3.4), согласно (3.3), получаем $u^{*}=0$ и по формулам линейной теории сферических оболочек определяем деформации $\left(\varepsilon^{*}\right)$ и нормальные усилия $\left(T^{*}\right)$, действующие в вертикальном и горизонтальном направлениях; остальные усилия и моменты равны нулю.

$$
\varepsilon_{1}^{*}=\varepsilon_{2}^{*}=\frac{w^{*}}{R}=\frac{1-v}{2} \frac{q_{0} R}{E h} ; \quad T_{1}^{*}=T_{2}^{*}=\frac{q_{0} R}{2},
$$

где индексы 1 и 2 относятся соответственно к вертикальному и горизонтальному направлениям роговицы.

Заметим, что решение (3.4), (3.5) строго удовлетворяет уравнениям (3.2) общей теории сферических оболочек, являясь, по существу, безмоментным. 
Решение однородной системы (3.2) получено в специальных функциях и приводит к следующим расчетным формулам:

$$
\begin{aligned}
& w=C_{1} \text { ber }(\alpha \theta)+C_{2} \text { bei }(\alpha \theta) \text {, } \\
& u=-\frac{1+v}{2 b^{2}}\left[C_{1} \operatorname{bei}_{\theta}^{\prime}(\alpha \theta)-C_{2} \operatorname{ber}_{\theta}^{\prime}(\alpha \theta)\right] \text {, } \\
& \theta=-\frac{1}{R}\left\{C_{1}\left[\operatorname{ber}_{\theta}^{\prime}(\alpha \theta)+\frac{1+v}{2 b^{2}} \operatorname{bei}_{\theta}^{\prime}(\alpha \theta)\right]+\right. \\
& \left.+C_{2}\left[\operatorname{bei}_{\theta}^{\prime}(\alpha \theta)-\frac{1+v}{2 b^{2}} \operatorname{ber}_{\theta}^{\prime}(\alpha \theta)\right]\right\} \text {. } \\
& T_{1}=\frac{\cdot E h}{R} \frac{\operatorname{ctg} \theta}{2 b^{2}}\left[C_{1} \operatorname{bei}_{\theta}^{\prime}(\alpha \theta)-C_{2} \operatorname{ber}_{\theta}^{\prime}(\alpha \theta)\right] \text {, } \\
& T_{2}=\frac{E h}{R} w-T_{1}, \\
& M_{1}=\frac{2 b^{2} D}{R^{2}}\left\{C _ { 1 } \left[\text { bei }(\alpha \theta)-\frac{1+v}{2 b^{2}} \text { ber }(\alpha \theta)+\frac{1-v}{2 b^{2}} \operatorname{ctg} \theta \times\right.\right. \\
& \left.\times\left(\operatorname{ber}_{\theta}^{\prime}(\alpha \theta)+\frac{1+v}{2 b^{2}} \operatorname{bei}_{\theta}^{\prime}(\alpha \theta)\right)\right]+C_{2}[\operatorname{ber}(\alpha \theta)+ \\
& \left.\left.+\frac{1+v}{2 b^{2}} \text { bei }(\alpha \theta)-\frac{1-v}{2 b^{2}} \operatorname{ctg} \theta\left(\operatorname{bei}_{\theta}^{\prime}(\alpha \theta)-\frac{1+v}{2 b^{2}} \operatorname{ber}_{\theta}^{\prime}(\alpha \theta)\right)\right]\right\} \text {, } \\
& M_{2}=\nu M_{1}+\frac{E h^{3}}{12 R} \vartheta \operatorname{ctg} \theta \text {, }
\end{aligned}
$$

где $C_{1}$ и $C_{2}$ - постоянные интегрирования; $2 b^{2}=\frac{R}{h} \sqrt{12\left(1-v^{2}\right)}-$ большой параметр, $D=\frac{E h^{3}}{12\left(1-v^{2}\right)}-$ цилиндрическая жесткость; $\theta$ и $M-$ угол поворота и изгибающий момент оболочки.

Напряженно-деформированное состояние оболочки II (склера) определяется на основе решения, полученного асимптотическим методом интегрнрования комплексных уравнений В. В. Новожилова [ $\left.{ }^{9}\right]$. Условия стыковки решений на линии сопряжения оболочек I и II (роговица и склера) приводят к системе линейных уравнений относительно раднального усилия $Q_{0}$ и изгибающего момента $M_{0}$, действующих в оболочке I. Найденные таким образом значения $Q_{0}$ и $M_{0}$ определяют решение задачи о напряженно-деформированном состоянии роговицы.

В качестве примера приводятся результаты расчета напряженного состояния роговицы при следующих исходных данных: для оболочкн I (роговнца) $R^{(1)}=0,8 \mathrm{cм}, \Theta^{(1)}=0,675$ рад, $h^{(1)}=0.1$ см; для оболочкн II (склера) $R^{(2)}=1,1$ см, $\Theta^{(2)}=2,670$ рад, $h^{(2)}=0,1$ см.

Қак показывают расчеты, при нагрузке ВГД в роговнце имеет место напряженное состояние смешанного типа (изгиб и растяжение), тогда как в склере изгибные напряжения локализуются в приконтурной области около лимба роговицы; остальная поверхность склеры свободна от изгибных напряжений и находится под воздействием только растягивающих напряжений. Изгибные напряжения вызывают изгиб оболочек в горизонтальном и вертикальном направлениях и достигают наибольших значений вблизи сопряжения оболочек. Изгибные напряжения, как известно, методом фотоупругости не визуализируются. Растягивающие напряжения обусловливают натяжения биотканей рассматриваемых оболочек по вертикальному и горизонтальному направле- 


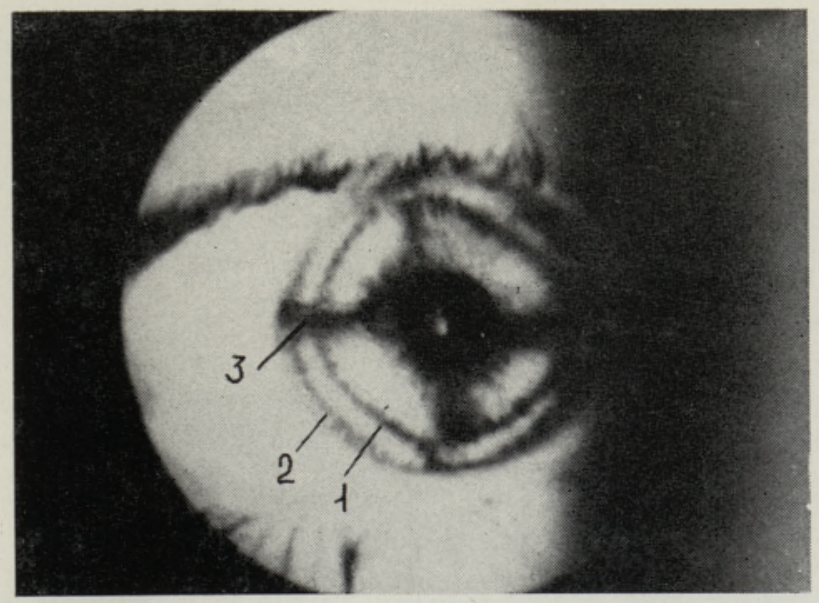

Рис. 2. Фотография изохроматического поля роговицы здорового глаза: 1 - изохрома 1-го порядка, 2 - изохрома 2 -го порядка, 3 - изоклина параметра $0^{\circ}$.

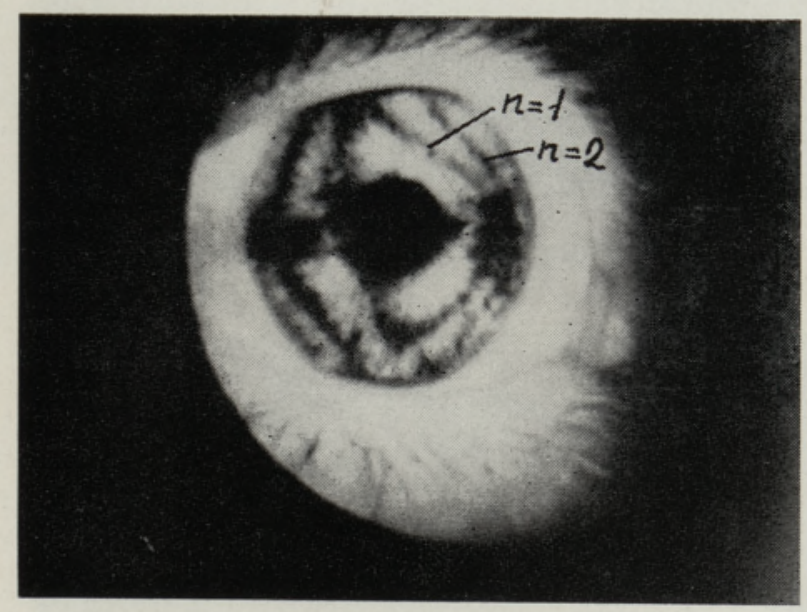

Рис. 7. Фотография поля изохром роговицы при близорукости.

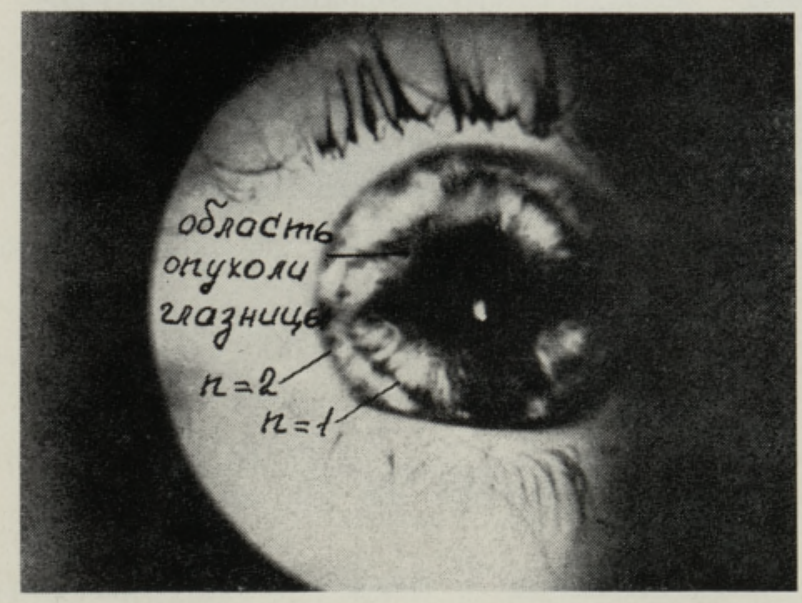

Рнс. 8. Фотография поля изохром при ретробульбарной опухоли, 


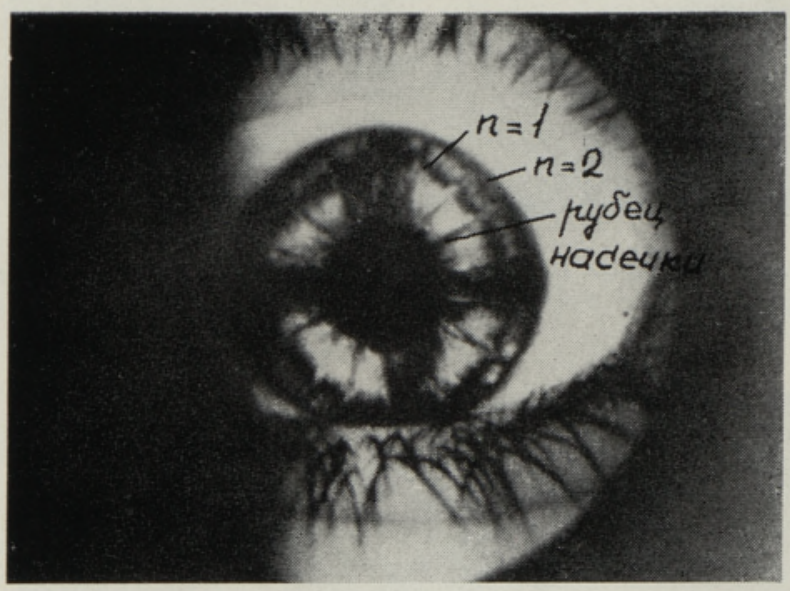

Рис. 9. Фотография изохром роговицы после операции кератотомни.

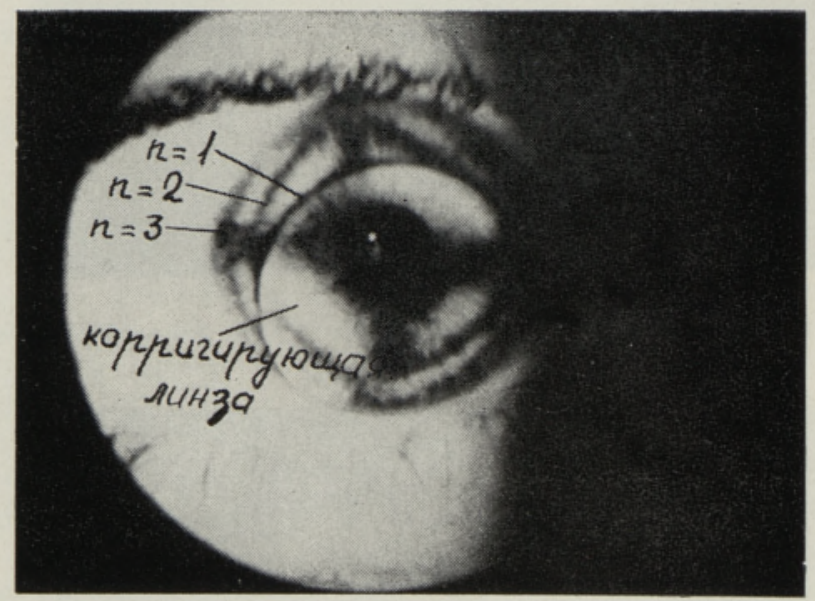

Рис. 10. Фотография изохром роговицы в случае давящей посадки корригирующей линзы. 
ниям. Эти напряжения распределены по толщине оболочек равномерно. Наличие растягивающих напряжений в роговице вызывает явление вынужденного двулучепреломления в биоткани, что визуализируется методом фотоупругости в виде полей изохром и изоклин. Графики распределения растягивающих напряжений $\sigma_{1 T}$ и $\sigma_{2 T}$, а также суммарных напряжений (изгибных и растягивающих) $\sigma_{1}$ и $\sigma_{2}$ по внешней и внутренней поверхности роговицы показаны на рис. 4. Анализ перемещений сопряженной системы оболочек роговица-склера показывает, что в результате воздействия ВГД диаметр склеральной оболочки (глазное яблоко) увеличивается на $9-10 \%$, тогда как поверхность роговицы несколько выполаживается. Для данной задачи методом численного моделирования было исследовано влияние различных соотношений модулей упругости биотканей роговицы и склеры $\left(\lambda=\frac{E_{\text {por. }}}{E_{\text {скл. }}}\right)$. на величины напряжений. Графики изменения разности главных напряжений растяжения по вертикальному направлению роговицы при вариации параметра $\lambda$ в пределах $1,0-2,0$ представлены на рис. 5 .

Выполненные расчеты и экспериментальные наблюдения позволили определить в первом приближении среднестатистическое значение коэффициента оптической чувствительности биоткани роговицы. Определение оптической разности хода по полю роговицы выполнено на основании статистической обработки результатов измерений обследовавшейся группы практически здоровых лиц. Величины $\delta$ устанавливались по методу компенсации с применением компенсатора Кокера. График распределения $\delta$ по горизонтальному направлению роговицы показан на рис. 6. На этом же графике представлено вычисленное распределе-
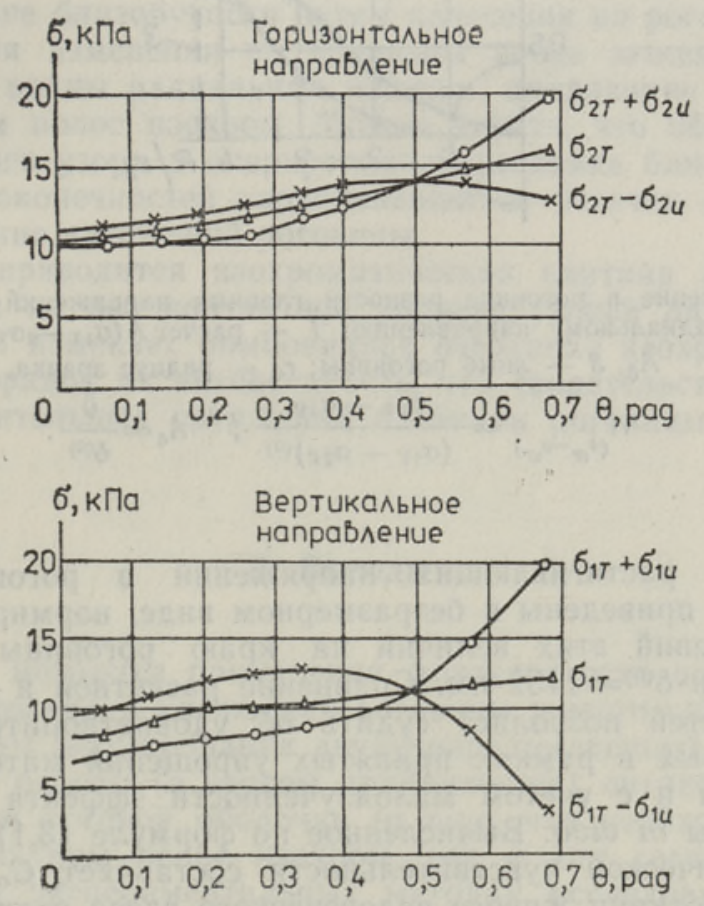

Рис. 4. Графики распределения напряжений по полю роговицы в вертикальном и горизонтальном направлениях - главные растягивающие напряжения (натяжения) $\sigma_{1 r}, \sigma_{2 r}$, изгибные напряжения $\sigma_{1 u}, \sigma_{2 u}$. 



\section{4. Пірименение метода фотоупругости к диагностике некоторых офтальмологических заболеваний}

В качестве иллюстрации возможных практических использований метода фотоупругости при офтальмологических заболеваниях нижє приводятся примеры характерных нарушений (по сравнению с «нор мой») изохроматической картины роговицы при отдельных видах забо леваний.

Для установления «нормы» двулучепреломляющего узора роговиць живого глаза проведены обследования 150 практически здоровых людей в возрасте от 18 до 20 лет. ВГД обследовавшихся составляло $2,52-2,92$ КПа. Типичное поле изохром (рис. 2) характеризуется, как правило, двумя порядками полос изохром зеленого цвета. Отклонения двулучепреломления у отдельных индивидуумов от указанной величины могут составлять не более половины полос зеленого цвета первого порядка в большую или меньшую сторону.

В случае сильной близорукости наблюдается (рис. 7) отличная от ромбовидного узора, но симметричная относительно горизонтальной оси, четырехугольная фигура очертания изохром. Со стороны носа порядок полос заметно возрастает и у лимба роговицы достигает значения $n^{\max }=3$.

На рис. 8 представлена изохроматическая картина поля роговицы при ретробульбарной опухоли глазницы. В зоне локализации опухоли отмечается искривление ромбовидного очертания узора полос. Увеличения натяжений роговицы (по сравнению с «нормой») в данном случае не наблюдается - порядок полос составляет $n_{\max }=2$.

Фотография поля изохром роговицы после перенесенной операции кератотомии показана на рис. 9. Операция кератотомии представляет собой исправление близорукости путем нанесения на роговицу радиальных насечек для изменения ее кривизны после заживления рубцов. На фотографии видны радиальные насечки, придающие волнистый характер контурам полос изохром. Можно видеть, что общее очертание изохроматического узора в оперированной роговице близко к «норме», однако вблизи оконечностей зарубцевавшихся насечек отмечается некоторое повышение натяжений роговицы.

На рис. 10 приводится изохроматическая картина поля роговицы при воздействии на нее контактной корригирующей линзы. Давление линзы несколько изменяет ромбовидное очертание изохром и увеличивает на один порядок их интенсивность, что свидетельствует о возникновении дополнительных натяжений биоткани роговицы.

\section{5. Выводы}

Разработана методика применения фотоупругости для анализа напряженного состояния и натяжений роговицы живого глаза. Выявлены основные факторы формирования двулучепреломляющей картины роговицы. Получены оценки (в первом приближении) оптико-механических свойств биоткани роговой оболочки in vivo, что необходимо как для расшифровки картины полос изохром, так и для совершенствования теоретических и экспериментальных методик исследований функциональных состояний роговицы.

Полученные в процессе работы материалы могут служить основой для создания методик практического применения метода фотоупругости в качестве диагностического средства глазных заболеваний. 
1. Stanworth, A. J. Exper. Biol. (JEB), 30, № 2, 164-170 (1953).

2. Cope, T., Wolbarst, M., Samanashi, B. J. Optic. Soc. Amer., 68, № 8, 1130-1132 (1978).

3. Zandman, F. Exper. Mech., 6, № 5, 19A-22A (1966).

4. Пеньков М. А., Кочина М. Л., Алтухер $Г$. М. Биофизика, хXVІІ, № 1, 313-316 (1982)

5. Водовозов А. М., Ковылин В. В. Офтальмологический ж., № 5, 260-262 (1983).

6. Mitcheson, J. J. Exper. Biol. (JEB), 30, № 3, 397-432 (1953).

7. Александров А. Я., Ахметзянов М. Х. Поляризационно-оптические методы механики деформируемого тела. М., «Наука», 1981.

8. Новожилов В. В. ДАН АН СССР, ХXVİ, № 6, 471-473 (1949).

9. Новожилов В. В. Теория тонких оболочек. Л., «Судпромгиз», 1962.

10. Stanworth, A., Naylor, E. J. Exper. Biol. (JEB), 30, № 2, 160-164 (1953).

\begin{abstract}
Военно-медицинская ордена Ленина
Краснознаменная академия им. С. М. Кирова

Ленинградский государственный университет

им. А. А. Жданова

Всесоюзный научно-исследовательский институт гидротехники им. Б. Е. Веденеева
\end{abstract}

Поступила в редакцию $4 /$ III 1987

Рижский институт травматологии

V. VOLKOV, S. VJAZMENSKI, L. MALOSEV, O. MAMAJEVA, V. PAVILAINEN, J. SAULGOZIS

\title{
SILMA SARVKESTA PINGETE UURIMINE IN VIVO FOTOELASTSUSMEETODIL
}

On uuritud silma sarvkesta kaksikmurdvaks mutumist ning isokliinide ja isokroomide kujunemist silmamuna sisesurve ja silmalihaste toimel. Pingeoptilise koefitsiendi määramiseks on vaadeldud sarvkesta kui sisesurvest tingitud sfäärilist koorikut. Näitena on toodud isokliinide ja isokroomide fotod mõnedest silmahaigustest.

V. VOLKOV, S. VYAZMENSKY, L. MALYSHEV, O. MAMAYEVA, V. PAVILAINEN, YU. SAULGOZIS

\section{PHOTOELASTIC INVESTIGATION OF STRESSES IN CORNEA OF A LIVING EYE}

Investigation results indicating the formation of the induced birefringence of human eye in vivo are presented. The phenomenological model of the mechanism of forming isochromatic and isoclinic patterns of the cornea is developed.

To establish the optical stress coefficient the stresses in the biologic tissue of the cornea are calculated by the linear theory of thin isotropic spherical compound shells. The eye-bulb is affected by intraocular pressure.

The method discussed is illustrated by examples of some eye deseases. 